\title{
Examining an Integrative Cognitive Model of Predicting Health App Use: Longitudinal Observational Study
}

\author{
Kwanho Kim ${ }^{1 *}, \mathrm{MA}$; Chul-Joo Lee ${ }^{2 *}, \mathrm{PhD}$ \\ ${ }^{1}$ Annenberg School for Communication, University of Pennsylvania, Philadelphia, PA, United States \\ ${ }^{2}$ Department of Communication, College of Social Science, Seoul National University, Seoul, Republic of Korea \\ *all authors contributed equally
}

\section{Corresponding Author:}

Kwanho Kim, MA

Annenberg School for Communication

University of Pennsylvania

3620 Walnut Street

Philadelphia, PA, 19104

United States

Phone: 12158987041

Email: kwanho.kim@asc.upenn.edu

\section{Abstract}

Background: Specifying the determinants of using health apps has been an important research topic for health scholars as health apps have proliferated during the past decade. Socioeconomic status (SES) has been revealed as a significant determinant of using health apps, but the cognitive mechanisms underlying the relationship between SES and health app use are unknown.

Objective: This study aims to examine the cognitive mechanisms underlying the relationships between SES and use of health apps, applying the integrative model of behavioral prediction (IM). The model hypothesizes the indirect influences of SES on intentions to use health apps, which in turn predict actual use of health apps. The relationships between SES and intentions to use health apps were assumed to be mediated by proximal variables (attitudes, perceived behavioral control [PBC], injunctive norms, and descriptive norms).

Methods: We conducted path analyses using data from a two-wave opt-in panel survey of Korean adults who knew about health apps. The number of respondents was 605 at baseline and 440 at follow-up. We compared our model with two alternative theoretical models based on modified IM to further clarify the roles of determinants of health app use.

Results: Attitudes $(\beta=.220, P<.001)$, PBC $(\beta=.461, P<.001)$, and injunctive norms $(\beta=.186, P<.001)$ were positively associated with intentions to use health apps, which, in turn, were positively related to actual use of health apps $(\beta=.106, P=.03)$. Income was positively associated with intentions to use health apps, and this relationship was mediated by attitudes $(\mathrm{B}=0.012,95 \% \mathrm{CI}$ $0.001-0.023)$ and PBC $(B=0.026,95 \%$ CI $0.004-0.048)$. Education was positively associated with descriptive norms $(\beta=.078$, $P=.03)$, but descriptive norms were not significantly related to intentions to use health apps. We also found that PBC interacted with attitudes $(B=0.043$, SE $0.022, P=.046)$ and jointly influenced intentions to use health apps, whereas the results did not support direct influences of education, income, and PBC on health app use.

Conclusions: We found that PBC over using health apps may be the most important factor in predicting health app use. This suggests the necessity of designing and promoting health apps in a user-friendly way. Our findings also imply that socioeconomic inequalities in using health apps may be reduced by increasing positive attitudes toward, and boosting PBC over, health app use among individuals with low income.

(JMIR Mhealth Uhealth 2021;9(2):e24539) doi: $\underline{10.2196 / 24539}$

\section{KEYWORDS}

mHealth; health apps; digital divide; integrative model of behavioral prediction; path analysis 


\section{Introduction}

\section{Overview}

Health-related apps (health apps) are software on mobile devices providing various health care services [1,2]. Health apps have been considered new communication technologies that may substantially affect public health [1]. As of 2019, it has been estimated that $54.2 \%$ of US adults have health apps [3]; use of health apps can promote prohealth behaviors such as healthy eating [4-6] and weight loss [7,8], though effectiveness of each app may vary [9]. To assess the public health impacts of health apps, scholars have explored predictors of health app use.

Several pioneering studies have reported that demographic factors, including education and income, which are widely used indicators of socioeconomic status (SES), are positively associated with use of health apps [10-13]. Furthermore, some studies examined the roles of SES and cognitive factors as potential determinants of health app use $[11,14]$. Nevertheless, they did not theorize how SES and cognitive factors are related to each other in predicting health app use. As a result, it is still largely unknown why people with higher SES are more apt to use health apps than those with lower SES.

To address this issue, we propose a comprehensive model of predicting health app use that utilizes the integrative model of behavioral prediction (IM). This theory has been frequently adopted by health researchers to explain the cognitive mechanisms underlying people's health-related behaviors (eg, safe sex, cancer screening, quitting smoking) $[15,16]$. We test our model with data from a two-wave panel survey of South Korean adults. Last but not least, to further investigate the relationships between determinants of behaviors in IM, we compare our model with other competing models based on modified IM.

\section{Applying IM to the Context of Health App Use}

IM succeeds the theory of reasoned action [17] and the theory of planned behavior [18]; all three theories posit that behavioral intention is the primary determinant of a behavior $[15,16]$. Then, IM theorizes the roles of two different types of variables in predicting behaviors: proximal and distal variables. Only proximal variables directly affect intentions; the influences of distal variables on intentions are mediated by proximal variables.

IM claims that intentions can be sufficiently explained with three proximal variables: (1) attitudes (overall favorableness) toward a behavior, (2) subjective norms regarding a behavior, consisting of injunctive norms (perceptions of what is approved or disapproved by close others) and descriptive norms (perceptions about prevalence of a behavior among close others) on a behavior, and (3) perceived behavioral control (PBC) over a behavior (self-evaluated capability in performing a behavior) [16]. Adopting this argument, we posit hypotheses as follows:

H1-H3: Attitudes toward (H1), subjective norms regarding (H2), and PBC over (H3) health app use will be positively associated with intentions to use health apps, which, in turn, will be associated with increased health app use.
However, resources available for those who attempt to change people's health-related behaviors are limited. Specifying the proximal variable that most strongly influences a target behavior is necessary to find the most efficient way of affecting it [16]. When it comes to health apps, app developers can devise better promotion strategies and improve the design of their apps more efficiently than they do without such knowledge. For instance, if app developers know that PBC is the strongest determinant of adopting and using health apps, and if the developers have a tight budget, they will want to focus on making apps easy to use. This would be the most cost-efficient way of developing the apps. Hence, we pose the following research question:

RQ1: Which proximal variable will most strongly predict intentions to use health apps?

\section{Applying IM to Investigate Digital Divide in Using Health Apps}

Next, IM categorizes all potential determinants of behaviors other than the proximal variables as distal variables. The relationships between distal variables and intentions are hypothesized to be fully mediated by the proximal variables [16]. Thus, SES is conceptualized as a distal variable in IM. Why, then, does this study concentrate on the relationship between SES and health app use?

Investigating whether and how SES relates to health app use is important in order to know how to reduce the digital divide in using the apps. The digital divide refers to inequalities in accessing and utilizing information and communication technologies (ICT) across different social groups [19-22]; this has been revealed as a substantial cause of health disparities [23-25]. Evidence has supported the digital divide in using health apps due to SES [10-13].

Given that cognitive approaches have contributed to understanding the diffusion of ICT [26,27], theorizing the cognitive mechanisms behind the digital divide in using health apps is important to find effective ways of diminishing it.

Nevertheless, former studies have not asked how SES is associated with cognitive factors in predicting health app use. For example, Chae (2018) juxtaposed education and income with cognitive factors in predicting health app use but did not theorize the relationship between SES and cognitive factors [11]; Mackert et al (2016) controlled for demographics when testing the potential connection between health information literacy (ie, cognitive capacity for processing health information) and use of health ICT including health apps [14]. In sum, we propose the following hypothesis:

H4: Individuals' SES (education and income) will be positively associated with intentions to use health apps through the mediation of proximal variables.

Moreover, in the following research question, we specify the proximal variable that most strongly mediates the influences of SES on behavioral intentions. This will show what will be the most efficient way of decreasing the gaps in use of health apps across people with different SES:

RQ2: Which proximal variable will most strongly mediate the effects of SES on intentions to use health apps? 


\section{Revisiting the Roles of Distal Variables and PBC in IM}

Though IM is considered well-established, there are three ongoing controversies regarding the roles of distal variables and PBC in the model [16]. This study will test those competing arguments in the context of health app use.

First, a handful of health studies have found evidence supporting significant direct influences of distal variables on behavioral intentions and actual behaviors [28-30]. Those findings confront two fundamental assumptions of IM: (1) indirect relationships between distal variables and intentions and (2) behavioral intention as the primary determinant of behavior. Given those prior findings, we revisit the role of distal variables in the context of health app use as follows:

RQ3: Will SES be directly associated with intentions to use health apps or actual use of health apps?

Next, the original IM argues that the influence of PBC on behaviors is fully mediated by intentions, and it has been consistently supported by evidence [16,31]. However, a few researchers have suggested that PBC may be directly related to behaviors, bypassing the mediation of intentions, to the extent that PBC may reflect actual control over behaviors [31]. Some health studies have reported evidence supporting this competing argument [32-35]. To examine these potential direct influences of PBC on behaviors in the context of health apps, we propose the following research question:

RQ4: Will PBC be directly associated with actual use of health apps?

Lastly, it has been proposed that PBC may moderate the attitudes-intentions and subjective norms-intentions relationships [31,36-38]. The logic of this hypothesis is that positive attitudes and subjective norms may not translate into a behavior when people do not feel that they have sufficient control over (not) conducting the behavior $[31,38]$. This issue has not been addressed in the context of health apps, and findings from health studies have been mixed. For instance, PBC significantly moderated only attitudes-intentions relationships in the context of prostate-specific antigen testing, whereas only norms-intentions relationships were significantly moderated by PBC in the context of performing regular exercise [37]. Given these mixed findings and the lack of studies addressing this issue in the health app context, we ask the following question:

RQ5: Will PBC moderate attitudes-intentions and subjective norms-intentions relationships in the context of health app use?

\section{Methods}

\section{Survey Data}

This study is a part of a larger health communication research project conducted in South Korea. A two-wave opt-in panel survey of Korean adults was collected by a survey company (Embrain). 1718 respondents participated in the baseline survey in February 2016 (completion rate=1718/2415=71.1\%). 1304 of those respondents cooperated with a follow-up survey in April 2016 (attrition rate $=414 / 1718=24.1 \%$ ). The final sample size decreased to 605 at baseline and 440 at follow-up because we included only those who answered "yes" for the following filter question: "Do you know about health apps? Health app refers to health-related software installed on a smartphone or tablet PC to help users to manage their health behaviors."

If we had provided a brief explanation about health apps, we could have measured proximal variables and intentions even among the respondents who did not know about the apps. However, measures based on very little knowledge have been considered "tentative"; those should be distinguished from "real" views based on good knowledge about the topic [39]. We adopted the filtered sample that allowed us to focus on those real views about health apps; this increased the validity of our measures and findings [39-41].

When it comes to demographic characteristics, the full $(\mathrm{N}=1718)$ and filtered $(\mathrm{N}=605)$ samples significantly differed only in years of education (full sample mean 14.97 years, 95\% CI 14.86-15.08; filtered sample mean 15.30 years, 95\% CI 15.13-15.47). The selected baseline $(\mathrm{N}=605)$ and follow-up $(\mathrm{N}=440)$ respondents were not significantly different with regard to demographic characteristics. For descriptive statistics, see Table 1. 
Table 1. Descriptive statistics of variables.

\begin{tabular}{|c|c|c|}
\hline Characteristic & Baseline $(\mathrm{n}=605)$ & Follow-up $(n=440)$ \\
\hline Age (years), mean (SD) & $39.00(10.94)$ & $40.42(10.81)$ \\
\hline Male sex, $\mathrm{n}(\%)$ & $292(48.3)$ & $210(47.7)$ \\
\hline Employment status (employed), n (\%) & $431(71.2)$ & $326(74.1)$ \\
\hline Marital status (married), n (\%) & $365(60.3)$ & $284(64.5)$ \\
\hline Years of education, mean (SD) & $15.30(2.14)$ & $15.32(2.22)$ \\
\hline Monthly household income (US $\$)^{\mathrm{a}}$, mean (SD) & $3910.59(1627.45)$ & $3920.45(1600.84)$ \\
\hline Body mass index & $23.10(3.15)$ & $23.16(3.02)$ \\
\hline Perceived health status ${ }^{\mathrm{b}}$, mean (SD) & $3.41(0.75)$ & $3.40(0.75)$ \\
\hline Other source use ${ }^{\mathrm{c}}$, mean (SD) & $2.64(0.50)$ & $2.66(0.50)$ \\
\hline Attitudes ${ }^{\mathrm{d}}$, mean $(\mathrm{SD})$ & $5.01(0.98)$ & $-^{\mathrm{e}}$ \\
\hline Injunctive norms ${ }^{\mathrm{f}}$, mean (SD) & $2.69(0.65)$ & - \\
\hline Descriptive norms ${ }^{\mathrm{g}}$, mean $(\mathrm{SD})$ & $2.01(0.70)$ & - \\
\hline Perceived behavioral control ${ }^{\mathrm{h}}$, mean (SD) & $3.41(1.01)$ & - \\
\hline Intentions to use health apps ${ }^{\mathrm{i}}$, mean (SD) & $3.32(1.07)$ & - \\
\hline Types of health apps in use $\mathrm{j}^{\mathrm{j}}$, mean (SD) & $2.01(1.25)$ & $1.80(1.57)$ \\
\hline Frequency of health app use ${ }^{\mathrm{k}}$, mean (SD) & $2.83(2.47)$ & $2.50(2.54)$ \\
\hline Health app use (composite measure) ${ }^{1}$, mean (SD) & $0.00(1.56)$ & $0.00(1.65)$ \\
\hline
\end{tabular}

${ }^{\mathrm{a}}$ Income was measured on an 8-point scale: 1=US $\$ 990$ or lower to 8=US $\$ 7000$ or higher. We averaged household income after recoding the response options into a ratio variable (eg, $2=$ US $\$ 1000$ to $\$ 1990$ was recoded as US $\$ 1500$ ).

${ }^{\mathrm{b}} 1=$ very bad to $5=$ very good.

${ }^{\mathrm{c}}$ Mean of seven items tapping use of health information sources other than health apps. $1=$ never, $4=$ frequently.

${ }^{\mathrm{d}}$ Mean of two attitudes items. $1=$ very negative, $7=$ very positive.

${ }^{\mathrm{e}}$ Not available.

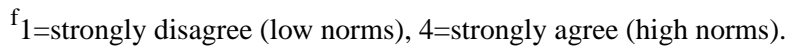

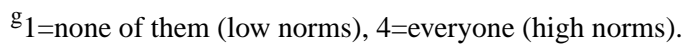

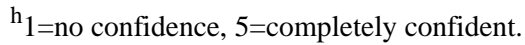

${ }^{\mathrm{i}} 1=$ extremely low, $5=$ extremely high.

${ }^{\mathrm{j}}$ Sum of 14 items of a certain type of health app use. $0=$ no (no use), $1=$ yes (use).

${ }^{\mathrm{k}} 0=$ never to $7=$ everyday.

${ }^{1}$ Sum of the standardized values of frequency of health app use and the number of types of health apps in use.

\section{Measures}

We created survey items capturing IM-related variables in the context of health apps, following the guidelines from Fishbein and Ajzen (2010) [16]. Moreover, we developed a composite measure of health app use following prior studies' measure creation procedures $[42,43]$.

\section{Distal Variables (Baseline)}

We adopted education and income as proxies of SES. For education, we asked respondents their highest level of schooling completed ( $1=$ elementary school not completed to $8=$ doctorate). The response options were recoded into years usually required to finish a given type of education in the nation. Income was captured employing an 8-point scale (1=US $\$ 990$ or lower to $8=$ US $\$ 7000$ or higher) and then recoded using the midpoint of

each option (eg, 2=US $\$ 1000$ to $\$ 1990$ was recoded as US \$1500) [44-47].

\section{Proximal Variables (Baseline)}

To measure attitudes toward using health apps, we averaged participants' answers to the following two 7-point semantic differential scale items $(r=0.81)$ : "Using mobile health apps in the next two months would be..." (1=very bad to 7=very good; $1=$ very unenjoyable to $7=$ very enjoyable).

We measured injunctive norms by asking respondents about their agreement with the following sentence: "Most people important to me think I should use health apps in the next two months ( $1=$ strongly disagree to $4=$ strongly agree)." Descriptive norms regarding health app use were captured by asking for respondents' perceptions of how many people important to them had employed health apps in the past two months $(1=$ none of 
them to $4=$ everyone). As the correlation between the two norms was only 0.28 , they were treated as separate variables in the analyses.

PBC was measured by asking how sure respondents were that they could use health apps on most days in the next two months if they wanted to ( $1=$ very unsure to $5=$ very sure).

\section{Intentions to Use Health Apps (Baseline)}

To capture intentions to use health apps, we asked participants to report their likelihood of using health apps in the next two months ( $1=$ very unlikely to $5=$ very likely).

\section{Health App Use (Baseline \& Follow-up)}

A composite scale of health app use was constructed by summing the standardized values of the two variables: the frequency of health app use and the number of types of health apps in use ( $r=0.21$ at baseline and 0.37 at follow-up). Each reflects the depth and breadth of health app use. The frequency was captured by asking participants about how often they used any health app ( $0=$ not at all to $7=$ all 7 days a week $)$. The other was measured with an additive index of 14 dichotomous items ( $0=$ no, $1=y e s$; the number of users at baseline in parentheses): (a) exercise \& fitness (539); (b) healthy diet (145); (c) weight control (141); (d) blood pressure (66); (e) blood sugar (31); (f) menstruation (132); (g) pregnancy (17); (h) baby care (30); (i) medication (12); (j) health information \& news (93); (k) mental health (35); (1) sleep (69); (m) quit smoking (20); and (n) beauty (28).

Figure 1. Conceptual framework of the analytic procedure. Bolded solid lines represent paths included in the basic model (Model A). Dashed lines represent paths added to the basic model in each competing model. None of the additional paths were adopted in the final model (Model A). Thin solid lines represent interaction relations added to each of Models D, E1, and E2. SES: socioeconomic status.

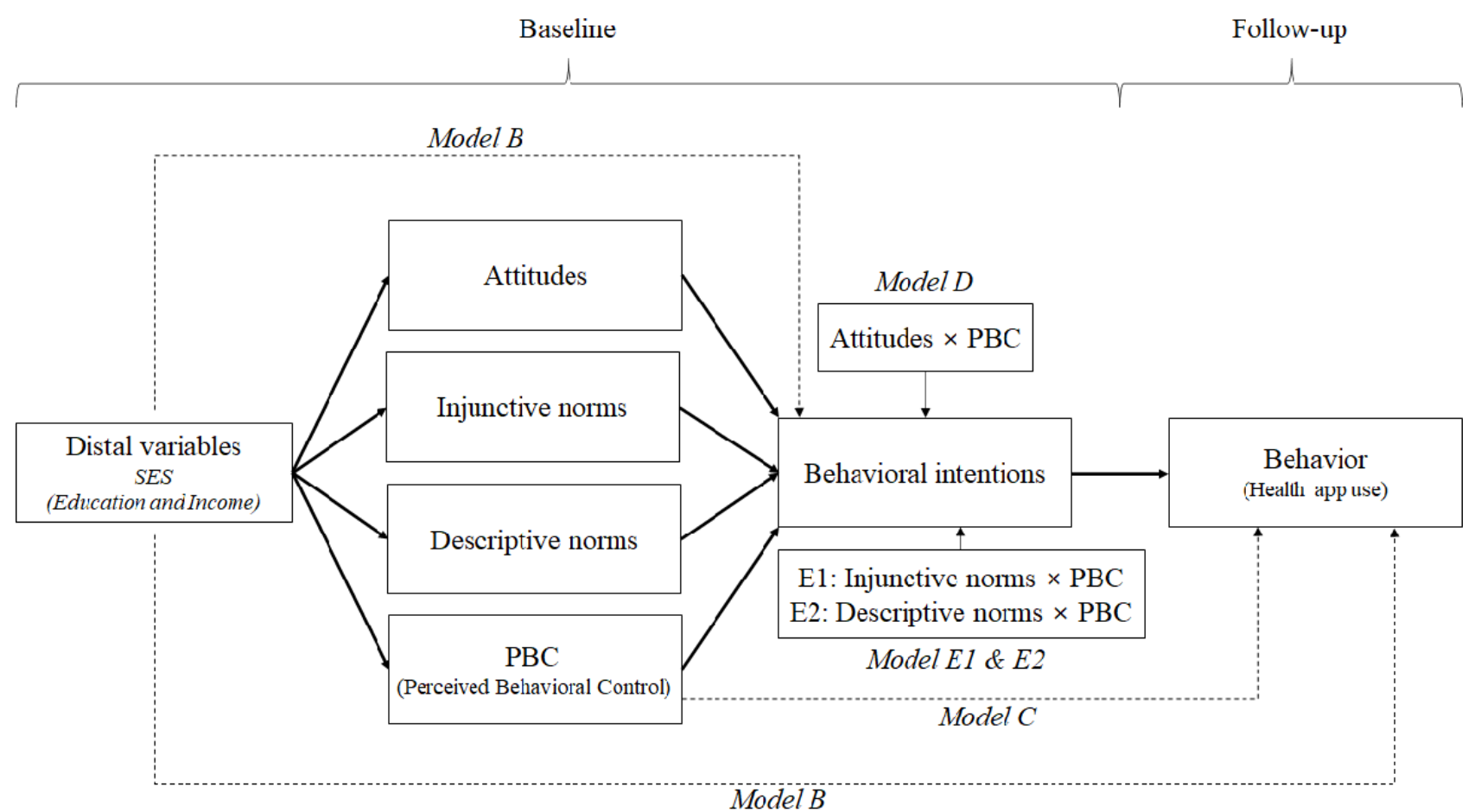

\section{Control Variables (Baseline)}

We measured demographic variables (age, sex, marital status, employment status, education, and monthly household income) and health-related variables (body mass index, perceived health status). Additionally, we captured use of health information sources other than health apps (hereafter, other source use) by averaging how often respondents obtained health information from the following seven sources ( $1=$ never to $4=$ frequently): printed media, TV, social media, health websites, general websites, friends, and health professionals.

\section{Analysis Strategy}

We performed path analyses via Mplus 8.3 (Muthén \& Muthén). Throughout all analyses, we controlled for all potential confounders described above and health app use at baseline (ie, past behavior). To evaluate model fit, we used a root mean quare error of approximation (RMSEA), a comparative fit (CFI), and a standardized root mean square residua ( with robust standard errors (MLR) method to test direct and interaction effects and bootstrapping (5000 samples) to examine indirect effects. Indirect relationships were considered significant when the bias-corrected $95 \%$ CI of unstandardized coefficients did not contain 0 [48]. We adopted the full information maximum likelihood method to handle missing values (aka, FIML and Direct ML). Figure 1 is a graphical illustration of the analysis strategy. 


\section{The Original IM-based Model}

We began by fitting an original IM-based model (hereafter, Model A). In Model A, health app use at follow-up was directly predicted only by intentions at baseline; the associations between intentions and the distal variables (education and income) were fully mediated by proximal variables. We estimated direct and indirect path coefficients to test original IM-based hypotheses (H1 to $\mathrm{H} 4)$; to compare the relative importance of proximal variables (RQ1 and RQ2), the differences between certain pairs of coefficients were examined with the $\chi^{2}$ difference test. For bivariate correlations of variables in Model A, see Table 2.

Table 2. Bivariate correlations of variables in Model A (best-fitting model).

\begin{tabular}{|c|c|c|c|c|c|c|c|c|c|}
\hline Variable & Education & Income & Attitudes & $\mathrm{IN}^{\mathrm{a}}$ & $\mathrm{DN}^{\mathrm{b}}$ & $\mathrm{PBC}^{\mathrm{C}}$ & Intentions & App use (B) ${ }^{\mathrm{d}}$ & App use $(F)^{\mathrm{e}}$ \\
\hline \multicolumn{10}{|l|}{ Education } \\
\hline$r$ & 1.000 & 0.157 & 0.083 & 0.052 & 0.094 & 0.021 & 0.086 & 0.078 & 0.090 \\
\hline$P$ value & ${ }_{-}^{f}$ & $<.001$ & .04 & .20 & .02 & .61 & .03 & .06 & .06 \\
\hline \multicolumn{10}{|l|}{ Income } \\
\hline$r$ & 0.157 & 1.000 & 0.151 & 0.087 & 0.078 & 0.137 & 0.097 & 0.122 & 0.097 \\
\hline$P$ value & $<.001$ & - & $<.001$ & .03 & .05 & $<.001$ & .02 & .003 & .04 \\
\hline \multicolumn{10}{|l|}{ Attitudes } \\
\hline$r$ & 0.083 & 0.151 & 1.000 & 0.482 & 0.227 & 0.582 & 0.584 & 0.396 & 0.268 \\
\hline$P$ value & .04 & $<.001$ & - & $<.001$ & $<.001$ & $<.001$ & $<.001$ & $<.001$ & $<.001$ \\
\hline \multicolumn{10}{|l|}{ IN } \\
\hline$r$ & 0.052 & 0.087 & 0.482 & 1.000 & 0.275 & 0.460 & 0.511 & 0.321 & 0.290 \\
\hline$P$ value & .20 & .03 & $<.001$ & - & $<.001$ & $<.001$ & $<.001$ & $<.001$ & $<.001$ \\
\hline \multicolumn{10}{|l|}{ DN } \\
\hline$r$ & 0.094 & 0.078 & 0.227 & 0.275 & 1.000 & 0.208 & 0.224 & 0.184 & 0.137 \\
\hline$P$ value & .02 & .05 & $<.001$ & $<.001$ & - & $<.001$ & $<.001$ & $<.001$ & .004 \\
\hline \multicolumn{10}{|l|}{ PBC } \\
\hline$r$ & 0.021 & 0.137 & 0.582 & 0.460 & 0.208 & 1.000 & 0.680 & 0.500 & 0.336 \\
\hline$P$ value & .61 & $<.001$ & $<.001$ & $<.001$ & $<.001$ & - & $<.001$ & $<.001$ & $<.001$ \\
\hline \multicolumn{10}{|l|}{ Intentions } \\
\hline$r$ & 0.086 & 0.097 & 0.584 & 0.511 & 0.224 & 0.680 & 1.000 & 0.581 & 0.368 \\
\hline$P$ value & .03 & .02 & $<.001$ & $<.001$ & $<.001$ & $<.001$ & - & $<.001$ & $<.001$ \\
\hline \multicolumn{10}{|l|}{ App use (B) } \\
\hline$r$ & 0.078 & 0.122 & 0.396 & 0.321 & 0.184 & 0.500 & 0.581 & 1.000 & 0.514 \\
\hline$P$ value & .06 & .003 & $<.001$ & $<.001$ & $<.001$ & $<.001$ & $<.001$ & - & $<.001$ \\
\hline \multicolumn{10}{|l|}{ App use (F) } \\
\hline$r$ & 0.090 & 0.097 & 0.268 & 0.290 & 0.137 & 0.336 & 0.368 & 0.514 & 1.000 \\
\hline$P$ value & .06 & .04 & $<.001$ & $<.001$ & .004 & $<.001$ & $<.001$ & $<.001$ & - \\
\hline
\end{tabular}

aN: injunctive norms.

${ }^{\mathrm{b}} \mathrm{DN}$ : descriptive norms.

${ }^{\mathrm{c}} \mathrm{PBC}$ : perceived behavioral control.

${ }^{\mathrm{d}} \mathrm{B}$ : baseline.

${ }^{\mathrm{e}} \mathrm{F}$ : follow-up.

${ }^{\mathrm{f}}$ Not applicable.

\section{Model Comparisons}

To address the theoretical controversies about IM, we first created Model B by modifying Model A to include direct links of distal variables (ie, education and income) with intentions and health app use. We compared Models A and B via the $\chi^{2}$ difference test (RQ3). Notably, since we used $\chi^{2}$ values from MLR estimations, the values were first adjusted using the scaling correction factors and then employed for the difference tests. 
The model fitting the data better was selected and then compared with Model C, constructed by allowing the selected model (Model A or B) to have a direct association between PBC and health app use (RQ4). The better-fitting model in the last comparison was chosen as the final model.

\section{Moderating Roles of PBC}

To assess the potential moderating roles of PBC (RQ5), we added three mean-centered interaction terms to the final model one at a time ("Attitudes $\times$ PBC," "Injunctive norms $\times$ PBC," and "Descriptive norms $\times$ PBC"; Models D, E1, and E2, respectively). We checked the significance of the interaction in each model.

\section{Results}

\section{The Original IM-based Model}

Model A fit the data well (Table 3). We found that intentions at baseline predicted health app use at follow-up $(B=0.164, S E$ $0.075, \beta=.106, P=.03)$. The effects of attitudes $(B=0.241$, SE
$0.039, \beta=.220, P<.001)(\mathrm{H} 1)$, injunctive norms $(\mathrm{B}=0.307, \mathrm{SE}$ $0.063, \beta=.186, P<.001)(\mathrm{H} 2)$, and PBC $(\mathrm{B}=0.491$, SE 0.046 , $\beta=.461, P<.001)(\mathrm{H} 3)$ on intentions were significant, whereas descriptive norms showed no significant association with intentions $(\mathrm{B}=0.041, \mathrm{SE} 0.046, \quad \beta=.027, \quad P=.38) \quad(\mathrm{H} 2)$. Accordingly, the indirect effects of attitudes $(B=0.040,95 \%$ CI $0.002-0.077)(\mathrm{H} 1)$, injunctive norms $(\mathrm{B}=0.050,95 \% \mathrm{CI}$ $0.001-0.102)(\mathrm{H} 2)$, and PBC (B=0.081, 95\% CI 0.007-0.154) (H3) on follow-up health app use were significant, while the indirect effects of descriptive norms on health app use were not $(\mathrm{B}=0.007,95 \% \mathrm{CI}-0.010$ to 0.023$)(\mathrm{H} 2)$. PBC was more strongly related to intentions than were attitudes $\left(\chi_{\text {diff, } 1}^{2}=11.3\right.$, $P<.001)$ and injunctive norms $\left(\chi_{\text {diff, } 1}^{2}=4.2, P=.04\right)$. However, the attitudes-intentions relationship was not significantly different from the injunctive norms-intentions relationship $\left(\chi_{\text {diff }, 1}^{2}=0.6, P=.43\right)$ (RQ1). In sum, H1 and H3 were supported and $\mathrm{H} 2$ was partially supported; $\mathrm{PBC}$ was revealed as the strongest proximal determinant of intentions to use health apps (RQ1).

Table 3. Measures of fit for six models.

\begin{tabular}{lllll}
\hline Models $^{\mathrm{a}}$ & Chi-square $(d f)^{\mathrm{b}}$ & RMSEA $^{\mathrm{c}}(90 \% \mathrm{CI})$ & CFI $^{\mathrm{d}}$ & SRMR $^{\mathrm{e}}$ \\
\hline Model A & $69.2(35)$ & $0.040(0.026-0.054)$ & 0.975 & 0.027 \\
Model B & $63.1(31)$ & $0.041(0.027-0.056)$ & 0.976 & 0.025 \\
Model C & $67.7(34)$ & $0.040(0.026-0.055)$ & 0.975 & 0.026 \\
Model D & $74.7(37)$ & $0.041(0.027-0.054)$ & 0.988 & 0.027 \\
Model E1 & $70.4(37)$ & $0.039(0.024-0.052)$ & 0.975 & 0.025 \\
Model E2 & $70.3(37)$ & $0.039(0.024-0.052)$ & 0.975 & 0.025 \\
\hline
\end{tabular}

${ }^{a}$ Model A: the original IM model; Model B: Model A with direct paths of distal variables on intentions and behavior; Model C: Model A with a direct path of perceived behavioral control (PBC) on behavior; Model D: Model A with an interaction term "Attitudes $\times$ PBC"; Model E1: Model A with an interaction term "Injunctive norms $\times$ PBC"; Model E2: Model A with an interaction term "Descriptive norms $\times$ PBC". Model A was the best-fitting model according to the step-by-step comparisons (step 1: Model A vs Model B; step 2: Model A vs Model C), therefore used for estimating coefficients. Model D, E1 and E2 are employed only for interaction tests.

${ }^{\mathrm{b}} \mathrm{All} \chi^{2}$ test results were significant $(P<.001)$.

${ }^{\mathrm{c}} \mathrm{RMSEA}$ : root mean square error of approximation.

${ }^{\mathrm{d}}$ CFI: comparative fit index.

${ }^{\text {e}}$ SRMR: standardized root mean square residual.

Education was positively associated with descriptive norms ( $\mathrm{B}=0.026$, SE 0.012, $\beta=.078, P=.03$ ), while income was positively related to attitudes $(B=0.050$, SE $0.022, \beta=.096$, $P=.02)$ and $\mathrm{PBC}(\mathrm{B}=0.053$, SE $0.022, \beta=.100, P=.02)$. The indirect associations between income and intentions through the mediation of attitudes $(\mathrm{B}=0.012,95 \% \mathrm{CI} 0.001-0.023)$ and PBC ( $\mathrm{B}=0.026,95 \%$ CI 0.004-0.048) were significant. However, the indirect relationships between education and intentions through the mediation of descriptive norms were not significant ( $\mathrm{B}=0.001,95 \% \mathrm{CI}-0.002$ to 0.004$)(\mathrm{H} 4)$. There was no significant difference between the income-attitudes relationship and the income-PBC relationship $\left(\chi_{\text {diff, } 1}^{2}=0.0, P=.88\right)(\mathrm{RQ} 2)$. Overall, we found some evidence supporting H4; the importance of proximal variables in predicting intentions to use health apps was not statistically different.

\section{Model Comparisons}

Model A turned out to be the best-fitting model, although Models B and C also fit the data well (Table 3). In the first round of comparison (Model A vs Model B), we found that Model B did not explain the data significantly better than Model A $\left(\chi_{\text {diff, }}^{2}=6.1, P=.19\right)$. That is, direct effects of distal variables on health app use were not supported (RQ3). The winning model, Model A, was further compared with Model C. Still, Model C did not fit the data significantly better than Model A $\left(\chi_{\text {diff, } 1}^{2}=1.4, P=.24\right)$. In other words, there was no evidence for direct associations of PBC with health app use (RQ4).

\section{Moderating Roles of PBC}

All models (Models D, E1, and E2) fit the data well (Table 3). The interaction between attitudes and $\mathrm{PBC}(\mathrm{B}=0.043$, SE 0.022 , $P=.046)$ was significant, while neither injunctive norms 
$(\mathrm{B}=0.012$, SE 0.036, $P=.75)$ nor descriptive norms $(\mathrm{B}=-0.032$, SE $0.047, P=.49$ ) significantly interacted with $\mathrm{PBC}$ in predicting intentions. The results from the Johnson-Neyman technique [49] showed that the $95 \% \mathrm{CI}$ of the conditional effect of attitudes on intentions was always above 0 (Figure 2). That is, at any range of $\mathrm{PBC}$, the influence of attitudes on intentions was significantly larger for people with higher PBC than for those with lower PBC (RQ5).

Figure 2. Conditional effect of attitudes on intentions to use health apps as a function of perceived behavioral control from the Johnson-Neyman technique. The $95 \%$ CI of the conditional effect of attitudes on intentions to use health apps is always above 0 , which means that the effect of attitudes is significantly positive for any value of PBC. PBC: perceived behavioral control.

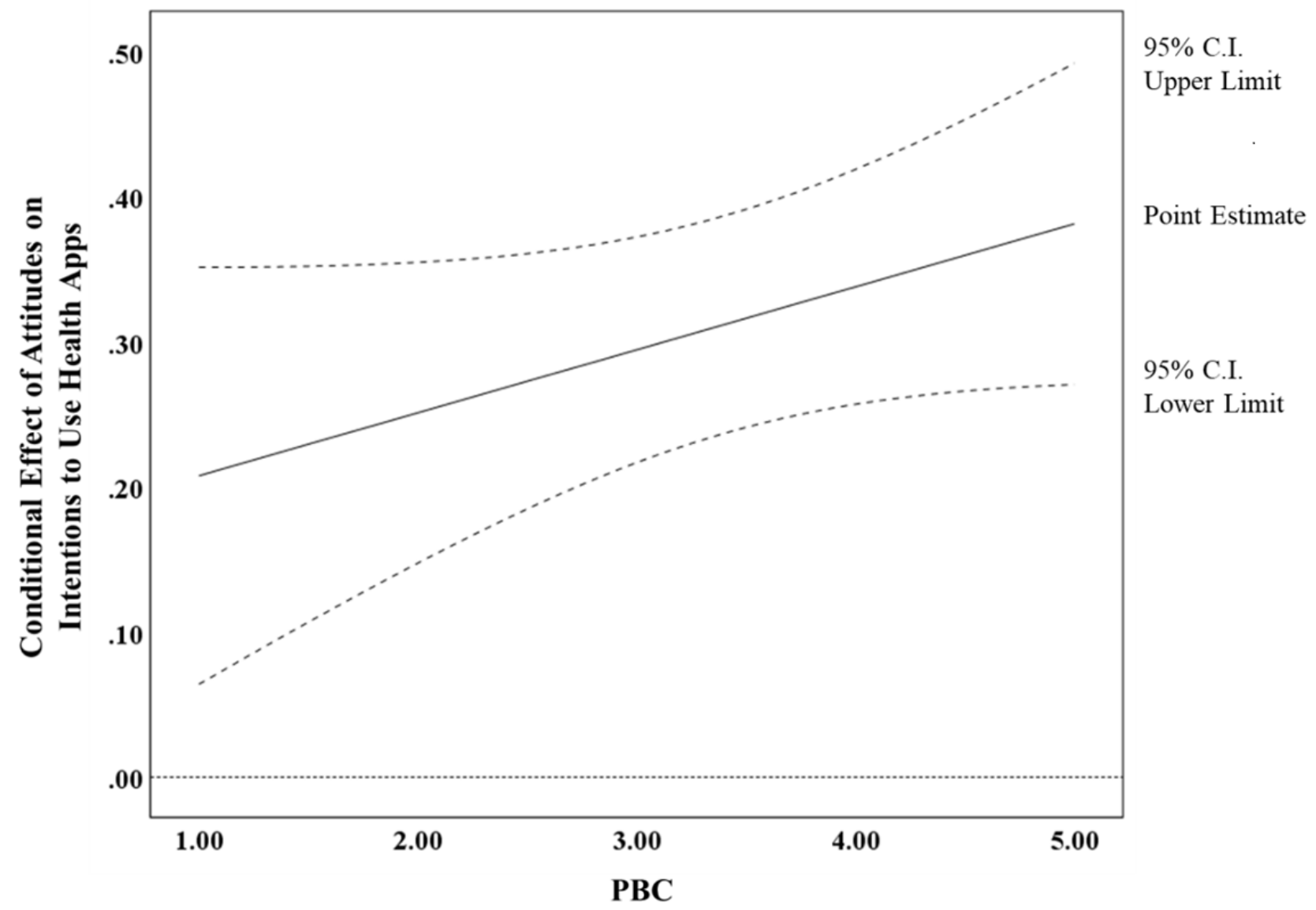

\section{Discussion}

As expected, attitudes, PBC, and injunctive norms were associated with intentions, which, in turn, were related to health app use. In contrast, descriptive norms were not significantly related to intentions; thus, they did not affect health app use. PBC positively interacted with attitudes and jointly influenced intention. The association between income and intention was mediated by attitudes and PBC; education was associated with descriptive norms, but the indirect relationship between education and intention was not significant.

Several limitations of this study should be discussed. First, as our data do not represent the Korean adult population, the generalizability of our findings may be restricted. Second, we used single-item questions to measure norms and PBC; future studies should consider employing multiple-item measures. Third, we cannot eliminate the concern of reverse causality because distal and proximal variables and intentions were measured at baseline. Fourth, our health app use measure cannot distinguish people using one app frequently from those who use many apps, but less frequently. However, our measure may better capture the actual pattern of health app use than binary measures (ie, use or no use) adopted in prior studies [11-14,50]. Lastly, future studies may need to control for factors possibly related to both a distal variable and health app use, such as health literacy, which may correlate to SES and health app use.

The theoretical implications of the findings should be highlighted. First, PBC was most strongly associated with intentions. This finding is inconsistent with a well-known argument that subjective norms are the most powerful predictors of behavioral intentions in collectivist cultures, including Korean, while attitudes are key determinants of intentions in individualistic cultures [51]. The relatively low penetration rate of health apps in Korea may explain this discrepancy [52,53].

PBC positively moderated the effects of attitudes on intentions; this has been repeatedly reported in other contexts [36,37,54]. In contrast, the effects of subjective norms on intentions were not moderated by PBC. This finding is not consistent with the prior evidence from Western countries [36,37,54,55]. Perhaps, as subjective norms are more robustly related to behavioral 
intentions in collectivist cultures than they are in individualistic cultures [51], the relationship might be stable regardless of PBC among Koreans.

We detected significant indirect effects of income on intentions to use health apps. The positive indirect effects of income on intentions mediated by attitudes and PBC were consistent with the key propositions of the diffusion of innovation theory [21]. It argues that individuals with high SES are more likely to be early adopters of technological innovations than people with low SES are, because the former are (1) financially and intellectually more capable of employing new technologies (ie, higher PBC) and (b) more open-minded to use those technologies than are the latter (ie, higher positive attitudes).

The findings of this study also have the following practical implications: First, this study underscores the importance of $\mathrm{PBC}$ in designing and promoting health app use. We discovered that $\mathrm{PBC}$ was the strongest determinant of intentions to use health apps and moderated the influences of attitudes on intentions. To boost PBC, an app should be designed and promoted in a user-friendly way (eg, using plain and easy-to-read language; providing easy-to-follow guidelines) so that potential users will not experience difficulties in using the app. Second, this study suggests that, to reduce the digital divide in health app use, public health professionals should instill in low-income individuals beliefs about expected positive outcomes from, and confidence in, using health apps. This strategy would thereby form favorable attitudes toward and greater PBC over health app use. Health apps are frequently monetized; thus, they are designed to target people with high SES to maximize their developers' profits [56,57]; given our findings, this trend is particularly worrisome because it can maintain or even worsen inequalities in public health outcomes.

\section{Acknowledgments}

This work was supported by the National Research Foundation of Korea (NRF-2018S1A5B8070398 to CJL) and the Institute of Communication Research at Seoul National University (to CJL).

\section{Conflicts of Interest}

None declared.

\section{References}

1. Becker S, Miron-Shatz T, Schumacher N, Krocza J, Diamantidis C, Albrecht U. mHealth 2.0: Experiences, Possibilities, and Perspectives. JMIR Mhealth Uhealth 2014 May 16;2(2):e24 [FREE Full text] [doi: 10.2196/mhealth.3328] [Medline: 25099752]

2. World Health Organization. New horizons for health through mobile technologies. 2011. URL: http://www.who.int/goe/ publications/goe mhealth web.pdf [accessed 2019-03-17]

3. National Cancer Institute. Health Information National Trends Survey 5 (HINTS 5), Cycle 3. 2019. URL: https://hints. cancer.gov/ [accessed 2020-03-07]

4. Mummah S, Robinson TN, Mathur M, Farzinkhou S, Sutton S, Gardner CD. Effect of a mobile app intervention on vegetable consumption in overweight adults: a randomized controlled trial. Int J Behav Nutr Phys Act 2017 Sep 15;14(1):125 [FREE Full text] [doi: 10.1186/s12966-017-0563-2] [Medline: 28915825]

5. Schoeppe S, Alley S, Van Lippevelde W, Bray NA, Williams SL, Duncan MJ, et al. Efficacy of interventions that use apps to improve diet, physical activity and sedentary behaviour: a systematic review. Int J Behav Nutr Phys Act 2016 Dec 07;13(1):127 [FREE Full text] [doi: 10.1186/s12966-016-0454-y] [Medline: 27927218]

6. West JH, Belvedere LM, Andreasen R, Frandsen C, Hall PC, Crookston BT. Controlling Your "App"etite: How Diet and Nutrition-Related Mobile Apps Lead to Behavior Change. JMIR Mhealth Uhealth 2017 Jul 10;5(7):e95 [FREE Full text] [doi: 10.2196/mhealth.7410] [Medline: 28694241]

7. Flores-Mateo G, Granado-Font E, Ferré-Grau C, Montaña-Carreras X. Mobile Phone Apps to Promote Weight Loss and Increase Physical Activity: A Systematic Review and Meta-Analysis. J Med Internet Res 2015 Nov;17(11):e253 [FREE Full text] [doi: 10.2196/jmir.4836] [Medline: 26554314]

8. Turner-McGrievy GM, Beets MW, Moore JB, Kaczynski AT, Barr-Anderson DJ, Tate DF. Comparison of traditional versus mobile app self-monitoring of physical activity and dietary intake among overweight adults participating in an mHealth weight loss program. J Am Med Inform Assoc 2013 May 01;20(3):513-518 [FREE Full text] [doi: 10.1136/amiajnl-2012-001510] [Medline: 23429637]

9. Milne-Ives M, Lam C, De Cock C, Van Velthoven MH, Meinert E. Mobile Apps for Health Behavior Change in Physical Activity, Diet, Drug and Alcohol Use, and Mental Health: Systematic Review. JMIR Mhealth Uhealth 2020 Mar 18;8(3):e17046 [FREE Full text] [doi: 10.2196/17046] [Medline: 32186518]

10. Bol N, Helberger N, Weert JCM. Differences in mobile health app use: A source of new digital inequalities? The Information Society 2018 Apr 26;34(3):183-193. [doi: 10.1080/01972243.2018.1438550]

11. Chae J. A Comprehensive Profile of Those Who Have Health-Related Apps. Health Educ Behav 2018 Aug;45(4):591-598. [doi: 10.1177/1090198117752784] [Medline: 29353544] 
12. Carroll JK, Moorhead A, Bond R, LeBlanc WG, Petrella RJ, Fiscella K. Who Uses Mobile Phone Health Apps and Does Use Matter? A Secondary Data Analytics Approach. J Med Internet Res 2017 Apr 19;19(4):e125 [FREE Full text] [doi: 10.2196/jmir.5604] [Medline: 28428170]

13. Krebs P, Duncan DT. Health App Use Among US Mobile Phone Owners: A National Survey. JMIR Mhealth Uhealth 2015 Nov;3(4):e101 [FREE Full text] [doi: 10.2196/mhealth.4924] [Medline: 26537656]

14. Mackert M, Mabry-Flynn A, Champlin S, Donovan EE, Pounders K. Health Literacy and Health Information Technology Adoption: The Potential for a New Digital Divide. J Med Internet Res 2016 Oct 04;18(10):e264 [FREE Full text] [doi: 10.2196/jmir.6349] [Medline: 27702738]

15. Fishbein M. The role of theory in HIV prevention. AIDS Care 2000 Jun;12(3):273-278. [doi: 10.1080/09540120050042918] [Medline: 10928203 ]

16. Fishbein M, Ajzen I. Predicting and changing behavior: the reasoned action approach. New York, NY: Psychology Press; 2009.

17. Ajzen I, Fishbein M. Understanding attitudes and predicting social behavior. Englewood Cliffs, NJ: Prentice-Hall; 1980.

18. Ajzen I. From intentions to actions: A theory of planned behavior. In: Kuhl J, Beckmann J, editors. Action control: From cognition to behavior. Heidelberg, Germany: Springer-Verlag; 1985:11-39.

19. Norris P. Digital divide: Civic engagement, information poverty, and the Internet worldwide. Cambridge, United Kingdom: Cambridge University Press; 2001.

20. Rains SA. Health at high speed: Broadband Internet access, health communication, and the digital divide. Communication Research 2008 Apr 14;35(3):283-297. [doi: 10.1177/0093650208315958]

21. Rogers EM. Diffusion of innovations (4th edition). New York, NY: Free Press; 2010.

22. Tsetsi E, Rains SA. Smartphone Internet access and use: Extending the digital divide and usage gap. Mobile Media \& Communication 2017 Jun 13;5(3):239-255. [doi: 10.1177/2050157917708329]

23. Bekalu M, Eggermont S, Viswanath K. HIV/AIDS Communication Inequalities and Associated Cognitive and Affective Outcomes: A Call for a Socioecological Approach to AIDS Communication in Sub-Saharan Africa. Health Commun 2017 Jun;32(6):685-694. [doi: 10.1080/10410236.2016.1167999] [Medline: 27367531]

24. Ramanadhan S, Nagler RH, McCloud R, Kohler R, Viswanath K. Graphic health warnings as activators of social networks: A field experiment among individuals of low socioeconomic position. Soc Sci Med 2017 Feb;175:219-227 [FREE Full text] [doi: 10.1016/j.socscimed.2016.12.044] [Medline: 28108053]

25. Viswanath K, Kreuter MW. Health disparities, communication inequalities, and eHealth. Am J Prev Med 2007 May;32(5 Suppl):S131-S133 [FREE Full text] [doi: 10.1016/j.amepre.2007.02.012] [Medline: 17466818]

26. Shaikh AA, Karjaluoto H. Computers in Human Behavior 2015 Aug;49:541-566. [doi: 10.1016/j.chb.2015.03.059]

27. Zhu JJH, He Z. Perceived characteristics, perceived needs, and perceived popularity: Adoption and use of the Internet in China. Communication Research 2002 Aug;29(4):466-495. [doi: 10.1177/0093650202029004005]

28. Mello S, Hovick SR. Predicting Behaviors to Reduce Toxic Chemical Exposures Among New and Expectant Mothers: The Role of Distal Variables Within the Integrative Model of Behavioral Prediction. Health Educ Behav 2016 Dec 09;43(6):705-715. [doi: 10.1177/1090198116637600] [Medline: 27179287]

29. Yzer MC, Cappella JN, Fishbein M, Hornik RC, Sayeed S, Ahern RK. The Role of Distal Variables in Behavior Change: Effects of Adolescents' Risk for Marijuana Use on Intention to Use Marijuana. J Appl Soc Psychol 2004 Jun 01;34(6):1229-1250 [FREE Full text] [doi: 10.1111/j.1559-1816.2004.tb02005.x] [Medline: 25132686]

30. Yzer MC, van den Putte B. Understanding smoking cessation: the role of smokers' quit history. Psychol Addict Behav 2006 Sep;20(3):356-361. [doi: 10.1037/0893-164X.20.3.356] [Medline: 16938076]

31. Yzer M. Perceived behavioral control in reasoned action theory: A dual-aspect interpretation. Ann Am Acad Pol Soc Sci 2012 Feb 10;640(1):101-117. [doi: 10.1177/0002716211423500]

32. Armitage CJ. Can the theory of planned behavior predict the maintenance of physical activity? Health Psychol 2005 May;24(3):235-245. [doi: 10.1037/0278-6133.24.3.235] [Medline: 15898858]

33. McEachan RRC, Conner M, Taylor NJ, Lawton RJ. Prospective prediction of health-related behaviours with the Theory of Planned Behaviour: a meta-analysis. Health Psychol Rev 2011 Sep;5(2):97-144. [doi: 10.1080/17437199.2010.521684]

34. Cooke R, Dahdah M, Norman P, French DP. How well does the theory of planned behaviour predict alcohol consumption? A systematic review and meta-analysis. Health Psychol Rev 2016 Jun 17;10(2):148-167 [FREE Full text] [doi: 10.1080/17437199.2014.947547] [Medline: 25089611]

35. Hamilton K, van Dongen A, Hagger MS. An extended theory of planned behavior for parent-for-child health behaviors: A meta-analysis. Health Psychol 2020 Oct;39(10):863-878. [doi: 10.1037/hea0000940] [Medline: 32597678]

36. Britt RK, Hatten KN, Chappuis SO. Perceived behavioral control, intention to get vaccinated, and usage of online information about the human papillomavirus vaccine. Health Psychol Behav Med 2014 Jan 01;2(1):52-65 [FREE Full text] [doi: 10.1080/21642850.2013.869175] [Medline: 25750767]

37. Martinez LS, Lewis N. The Moderated Influence of Perceived Behavioral Control on Intentions Among the General U.S. Population: Implications for Public Communication Campaigns. J Health Commun 2016 Sep 16;21(9):1006-1015 [FREE Full text] [doi: 10.1080/10810730.2016.1204378] [Medline: 27565188] 
38. Yzer MC. Does perceived control moderate attitudinal and normative effects on intention? A review of conceptual and methodological issues. In: Ajzen I, Albarracin D, Hornik RC, editors. Prediction and change of health behavior: Applying the reasoned action approach. Mahwah, NJ: Lawrence Erlbaum Associates Publishers; 2007:111-127.

39. Weisberg HF. The total survey error approach: A guide to the new science of survey research. Chicago, IL: The University of Chicago Press; 2005.

40. Bishop GF, Oldendick RW, Tuchfarber AJ, Bennett SE. Pseudo-opinions on public affairs. Public Opinion Quarterly 1980;44(2):198-209. [doi: 10.1086/268584]

41. Crano WD, Brewer MB, Lac A. Principles and methods of social research (third edition). New York, NY: Taylor \& Francis; 2014.

42. Hornik RC, Parvanta S, Mello S, Freres D, Kelly BJ, Schwartz JS. Effects of scanning (routine health information exposure) on cancer screening and prevention behaviors in the general population. J Health Commun 2013 Dec;18(12):1422-1435 [FREE Full text] [doi: 10.1080/10810730.2013.798381] [Medline: 24083417]

43. Moldovan-Johnson M, Martinez L, Lewis N, Freres D, Hornik RC. The role of patient-clinician information engagement and information seeking from nonmedical channels in fruit and vegetable intake among cancer patients. J Health Commun 2014 Dec 29;19(12):1359-1376 [FREE Full text] [doi: 10.1080/10810730.2014.906521] [Medline: 24875456]

44. Bjelland M, Brantsæter AL, Haugen M, Meltzer HM, Nystad W, Andersen LF. Changes and tracking of fruit, vegetables and sugar-sweetened beverages intake from 18 months to 7 years in the Norwegian Mother and Child Cohort Study. BMC Public Health 2013 Aug 30;13(1):793 [FREE Full text] [doi: 10.1186/1471-2458-13-793] [Medline: 24103398]

45. Hout M. Getting the most out of the GSS income measures.: University of California, Berkeley; 2004. URL: https://tinyurl. com/y5mj18vq [accessed 2021-01-14]

46. Pasta DJ. Learning when to be discrete: continuous vs. categorical predictors. Washington, D.C: SAS Global Forum; 2009. URL: https://support.sas.com/resources/papers/proceedings09/248-2009.pdf [accessed 2020-12-19]

47. Kelly BJ, Leader AE, Mittermaier DJ, Hornik RC, Cappella JN. The HPV vaccine and the media: how has the topic been covered and what are the effects on knowledge about the virus and cervical cancer? Patient Educ Couns 2009 Nov;77(2):308-313 [FREE Full text] [doi: 10.1016/j.pec.2009.03.018] [Medline: 19395221]

48. Kline RB. Principles and practice of structural equation modeling (fourth edition). New York, NY: Guilford Press; 2016.

49. Hayes AF. Introduction to mediation, moderation, and conditional process analysis: a regression-based approach (second edition). New York, NY: Guilford Press; 2018.

50. Bender MS, Choi J, Arai S, Paul SM, Gonzalez P, Fukuoka Y. Digital technology ownership, usage, and factors predicting downloading health apps among caucasian, filipino, korean, and latino americans: the digital link to health survey. JMIR Mhealth Uhealth 2014 Oct 22;2(4):e43 [FREE Full text] [doi: 10.2196/mhealth.3710] [Medline: 25339246]

51. Hassan LM, Shiu E, Parry S. Addressing the cross-country applicability of the theory of planned behaviour (TPB): A structured review of multi-country TPB studies. J Consumer Behav 2016;15(1):72-86. [doi: 10.1002/cb.1536]

52. Embrain TrendMonitor. Mobile healthcare report. 2013 Aug. URL: https://www.trendmonitor.co.kr/tmweb/trend/allTrend/ detail.do?bIdx=1079\&code=0501\&trendType=CKOREA [accessed 2021-01-14]

53. 2017 Survey on the Internet usage. Korea Internet \& Security Agency; 2018 May 2. URL: https://www.kisa.or.kr/eng/ usefulreport/surveyReport_View.jsp?mode=view\&p_No=4\&b_No=262\&d_No=81 [accessed 2021-01-14]

54. Dillard JP. An application of the integrative model to women's intention to be vaccinated against HPV: implications for message design. Health Commun 2011 Jul;26(5):479-486. [doi: 10.1080/10410236.2011.554170] [Medline: 21452094]

55. Yzer MC, van den Putte B. Control perceptions moderate attitudinal and normative effects on intention to quit smoking. Psychol Addict Behav 2014 Dec;28(4):1153-1161. [doi: 10.1037/a0037924] [Medline: 25243830]

56. Freudenberg N. Assessing the Public Health Impact of the mHealth App Business. Am J Public Health 2017 Nov;107(11):1694-1696. [doi: 10.2105/AJPH.2017.304083] [Medline: 29019765]

57. Grundy Q, Held F, Bero L. A Social Network Analysis of the Financial Links Backing Health and Fitness Apps. Am J Public Health 2017 Nov;107(11):1783-1788. [doi: 10.2105/ajph.2017.303995]

\section{Abbreviations}

CFI: comparative fit index

ICT: information and communication technology

IM: integrative model of behavioral prediction

MLR: maximum likelihood with robust standard errors

PBC: perceived behavioral control

RMSEA: root mean square error of approximation

SES: socioeconomic status

SRMR: standardized root mean square residual 
Edited by G Eysenbach; submitted 24.09.20; peer-reviewed by N Lewis, CC Chang; comments to author 14.10.20; revised version received 07.12.20; accepted 19.12.20; published 03.02.21

Please cite as:

Kim K, Lee CJ

Examining an Integrative Cognitive Model of Predicting Health App Use: Longitudinal Observational Study

JMIR Mhealth Uhealth 2021;9(2):e24539

URL: https://mhealth.jmir.org/2021/2/e24539

doi: $10.2196 / 24539$

PMID: 33533724

CKwanho Kim, Chul-Joo Lee. Originally published in JMIR mHealth and uHealth (http://mhealth.jmir.org), 03.02.2021. This is an open-access article distributed under the terms of the Creative Commons Attribution License (https://creativecommons.org/licenses/by/4.0/), which permits unrestricted use, distribution, and reproduction in any medium, provided the original work, first published in JMIR mHealth and uHealth, is properly cited. The complete bibliographic information, a link to the original publication on http://mhealth.jmir.org/, as well as this copyright and license information must be included. 